\title{
Refractory Materials for Flame Deflector Protection
}

\author{
Luz M. Calle, ${ }^{\text {i }}$ Paul E. Hintze, ${ }^{\text {ii }}$ Christopher R. Parlier, ${ }^{\text {iii }}$ Jeffrey W. Sampson, ${ }^{\text {iv }}$ \\ NASA, Kennedy Space Center, FL, 32899, U.S.A. \\ Jerome P. Curran, ${ }^{\mathrm{v}}$ Mark R. Kolody, ${ }^{\mathrm{vi}}$ Stephen A. Perusich ${ }^{\mathrm{vii}}$ \\ ASRC Aerospace, Kennedy Space Center, FL 32899, U.S.A.
}

\begin{abstract}
Fondu Fyre (FF) is currently the only refractory material qualified for use in the flame trench at KSC's Shuttle Launch Pads 39A and 39B. However, the material is not used as it was qualified and has undergone increasingly frequent and severe degradation due to the launch blasts. This degradation is costly as well as dangerous for launch infrastructure, crew and vehicle. The launch environment at $\mathrm{KSC}$ is unique. The refractory material is subject to the normal seacoast environment, is completely saturated with water before launch, and is subjected to vibrations and aggressive heat/blast conditions during launch. This report presents results comparing two alternate materials, Ultra-Tek FS gun mix and Kruzite GR Plus, with Fondu Fyre. The materials were subjected to bulk density, porosity, compression strength, modulus of rupture and thermal shock tests. In addition, test specimens were exposed to conditions meant to simulate the launch environment at KSC to help better understand how the materials will perform once installed.
\end{abstract}

\section{Nomenclature}

KSC $=$ Kennedy Space Center

$L C \quad=\quad$ Launch Complex

$M F D=$ Main Flame Deflector

$M O R=$ Modulus of Rupture

$S F D=$ Side Flame Deflector

$S R B=$ Solid Rocket Booster

SSME $\quad=$ Space Shuttle Main Engine

\footnotetext{
i Lead Scientist and Principal Investigator, NASA's Corrosion Technology Laboratory, Mail Stop: NE-L2-C.

ii Research Scientist, NASA's Corrosion Technology Laboratory, Mail Stop: NE-L2-C.

iii Engineer, NASA's Shuttle Ground Structural Systems Branch, Mail Stop: NE-M9.

${ }^{i v}$ Materials Test Engineer, Materials Testing and Corrosion Control Branch, Mail Stop: NE-L2-T.

${ }^{\vee}$ Corrosion Engineer, NASA's Corrosion Technology Laboratory, Mail Stop: ASRC-24.

${ }^{v i}$ Research Scientist, NASA's Corrosion Technology Laboratory, Mail Stop: ASRC-24.

${ }^{v i i}$ Chemical Engineer, NASA's Corrosion Technology Laboratory, Mail Stop: ASRC-24. 


\section{Introduction}

$\mathrm{T}$ he launch complexes at John F. Kennedy Space Center (KSC) are critical support facilities required for the safe and successful launch of vehicles into space. Most of these facilities are over 40 years old and are experiencing deterioration. With constant deterioration from launch heat/blast effects and environmental exposure, the refractory materials currently used in the NASA launch pad flame deflectors have become very susceptible to failure, resulting in large pieces of refractory materials breaking away from the steel base structure and being projected at high speeds during launches. Repair of these failures is a costly and time-consuming process. Improved materials and systems for use in launch pad flame deflectors will improve supportability in KSC launch facilities by reducing operational life cycles.

The flame deflector systems at LC 39A and LC 39B are critical to protect NASA's assets, that include the Space Shuttle, ground support equipment (GSE), and personnel. As the name implies, the system was designed to diverts rocket exhaust away from critical structures. During a launch, the flame deflector is subjected to a water deluge that dampens acoustic vibrations and high temperatures.

The flame deflectors consist of a steel base plate which is covered with a heat resistant material that protects the flame deflector from erosion, ablation and extreme temperatures that are produced by the rocket propulsion systems. If this refractory layer is compromised, deterioration to the flame deflector and other load bearing structures may result. Once compromised, the refractory material and flame deflector substructures can turn into unwanted projectiles known as foreign objects and debris (FOD) that can cause subsequent damage. Currently, Fondu Fyre WA-1G (supplied by the Pryor Giggey Co) is the only refractor material qualified for use. Figure 1 shows a schematic cross section of the flame deflector at launch complex 39A.. The flame deflector system consists of a flame trench, a main flame deflector (MFD), and a pair of side flame deflectors (SFD). The main flame deflector is designed in an in inverted, V-shaped configuration, is constructed from structural steel, and is covered with refractory concrete material. The thickness of the refractory concrete is 6 inches on the SRB side, 4.5 inches on the SSME side, and 4 inches on the side deflectors. One side of the inverted "V" deflects the flames and exhaust from the Space Shuttle main engine (SSME) and the opposite side deflects the flames and exhaust from the solid rocket boosters (SRBs). Additional protection is provided by the two movable side deflectors at the top of the trench (not shown in the figure). The SFD direct the SRB exhaust and are needed because the SRBs are very close to the side walls of the flame trench. The orbiter side of the flame deflectors is $38 \mathrm{ft} \mathrm{high,} 72 \mathrm{ft}$ long and $57 \mathrm{ft}$ wide. The SRB side of the flame deflector is $42 \mathrm{ft} \mathrm{high,} 42 \mathrm{ft}$ long and $57 \mathrm{ft}$ wide. The total mass of the asset is over 1 million lbs. ${ }^{1}$

There are multiple factors and mechanisms involved in the deterioration of the KSC launch pads. Hydrochloric acid $(\mathrm{HCl})$ from the SRB rocket exhaust coupled with the salty air ( $2500 \mathrm{ft}$ from the Atlantic Ocean) at KSC cause severe corrosion. High temperatures and large temperature variations over short intervals from convective and radiative heat transfer during liftoff lead to large thermal stresses in the refractory materials. Vibrations and particulate alumina $\left(\mathrm{Al}_{2} \mathrm{O}_{3}\right)$ impingement during takeoff cause erosion and spalling of the pads. Therefore, after each launch, the damaged flame deflectors undergo extensive examination and repair.

The launch environment is different in the SRB and SSME flame trenches. The SRB side has historically seen more damage than the SSME side due to the harsher conditions found there. This section gives a general overview of the launch environment.

The space shuttle has two SRBs, which exhaust in the north flame trench and three SSMEs, which exhaust towards the south. The SRBs have considerably more thrust, 3,300,000 lbs each, compared to the thrust of the SSMEs, 375,000 lbs each. The SRBs also burn hotter than the SSMEs, and produce aluminum oxide particles that can act as abrasives, or if they are near or above their melting point, may react with the refractory material. The SRBs impinge in two locations on the top of the flame deflector, as seen in Figure 2. The areas that receive direct impingement appear lighter, due to the presence of aluminum oxide particles in these locations. There are two side flame deflectors above the flame trench, shown in Figure 3. The SRBs exhaust impinges on the side deflectors before entering the main flame deflector. Examination of the impingement area shows that the refractory material experiences very different conditions than outside the impingement area. These differing conditions may even result in different failure mechanisms for the refractory material. For example, the bottom lip of the deflector appears to undergo more erosion than those areas farther up the deflector towards its apex.

The launch sequence itself affects the environment. Prior to launch, water is continuously flowed onto the refractory material. This procedural requirement ensures that the sound suppression system is operational and results in the refractory material being thoroughly saturated with water during launch. The sound suppression system releases approximately 300,000 gallons of water during launch, with a peak flow rate of 900,000 gallons per minute nine seconds after launch. ${ }^{2}$ The launch timeline is as follows: ${ }^{3}$ 
- The sound suppression water flow starts just before SSME ignition at $\mathrm{T}-6.6 \mathrm{~s}$.

- SSME ignition occurs at $\mathrm{T}-6.6 \mathrm{~s}$.

- $\quad$ SRB ignition occurs at $\mathrm{T}-0 \mathrm{~s}$.

- The shuttle clears the tower about 6 seconds after launch.

The current specification for refractory materials at the flame trench is KSC-SPEC-P-0012: Specification for Refractory Concrete. According to this specification, refractory materials selected for use in the flame trenches at $\mathrm{KSC}$ must possess the following requirements:

- Shall have a 7-day compressive strength of 4,500 psi,

- Shall have a 24 -hour strength of at least $90 \%$ of the 7 -day strength (4,050 psi),

- Shall be workable when placed in the trench,

- Shall resist degradation of thermal-protection characteristics caused by seacoast exposure,

- Shall not crack or spall after exposure to a launch environment,

- Shall not erode more than $1 / 8$ inch after exposure to a launch environment, and

- Shall have a maximum heat flux of $3,300 \mathrm{BTU} / \mathrm{ft}^{2}-\mathrm{s}=895 \mathrm{cal} / \mathrm{cm}^{2}-\mathrm{s}=3746 \mathrm{~W} / \mathrm{cm}^{2}$.

In this paper, testing results of some alternate refractory materials are compared with the physical properties of the current material, Fondu Fyre. Tests included bulk density, porosity, modulus of rupture, thermal shock and compression strength. Compression strength testing was performed on samples that were subjected to different environmental conditions: control specimens; specimens submerged in water; specimens submerged in acid; and specimens exposed at the Corrosion Technology Laboratory Beachside Atmospheric Exposure Facility. The tests selected for this study were thought to mimic the KSC environment better and provide more information than the compression strength called for in the standard.

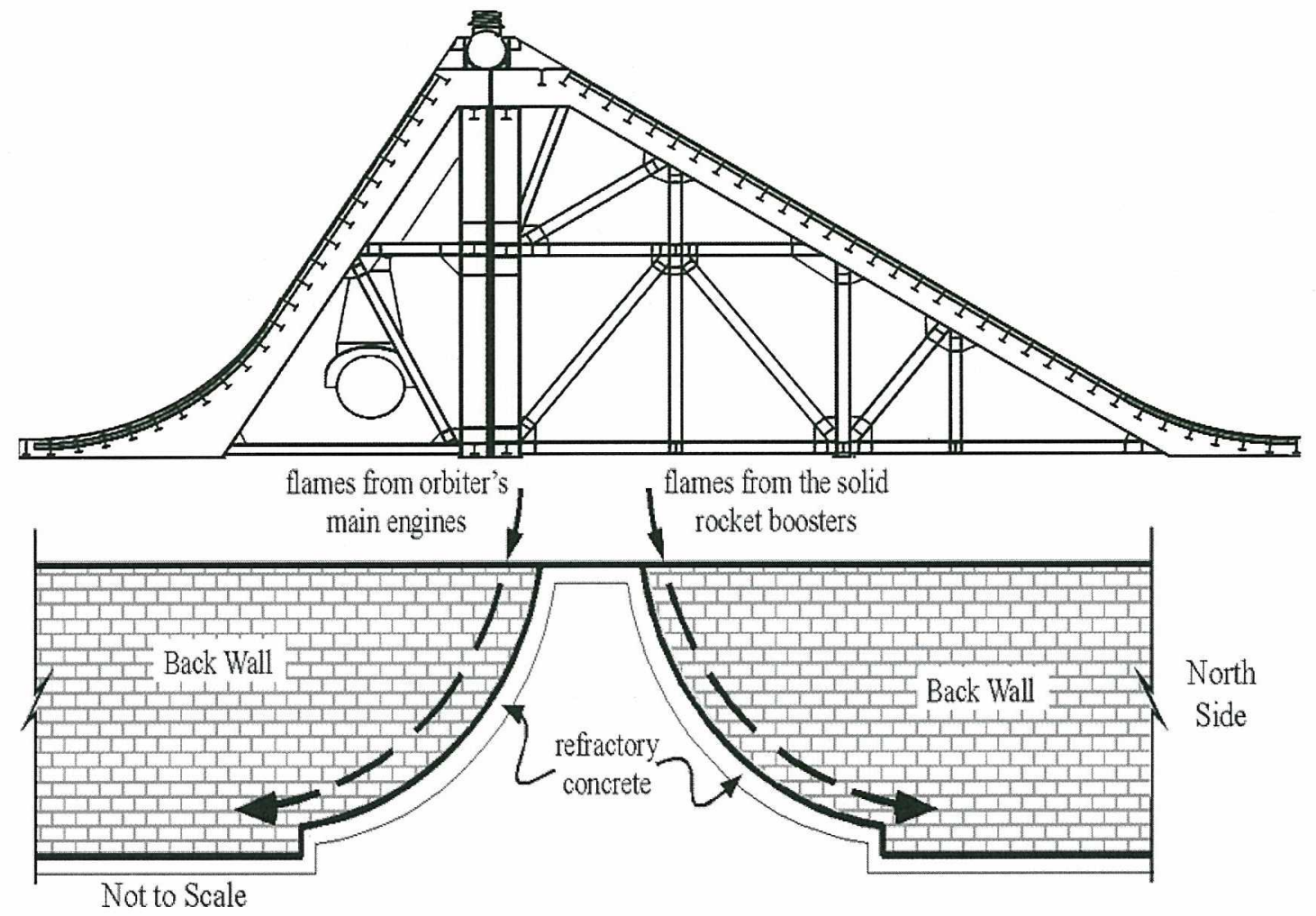

Figure 1. Schematic of the flame trench and deflector. 


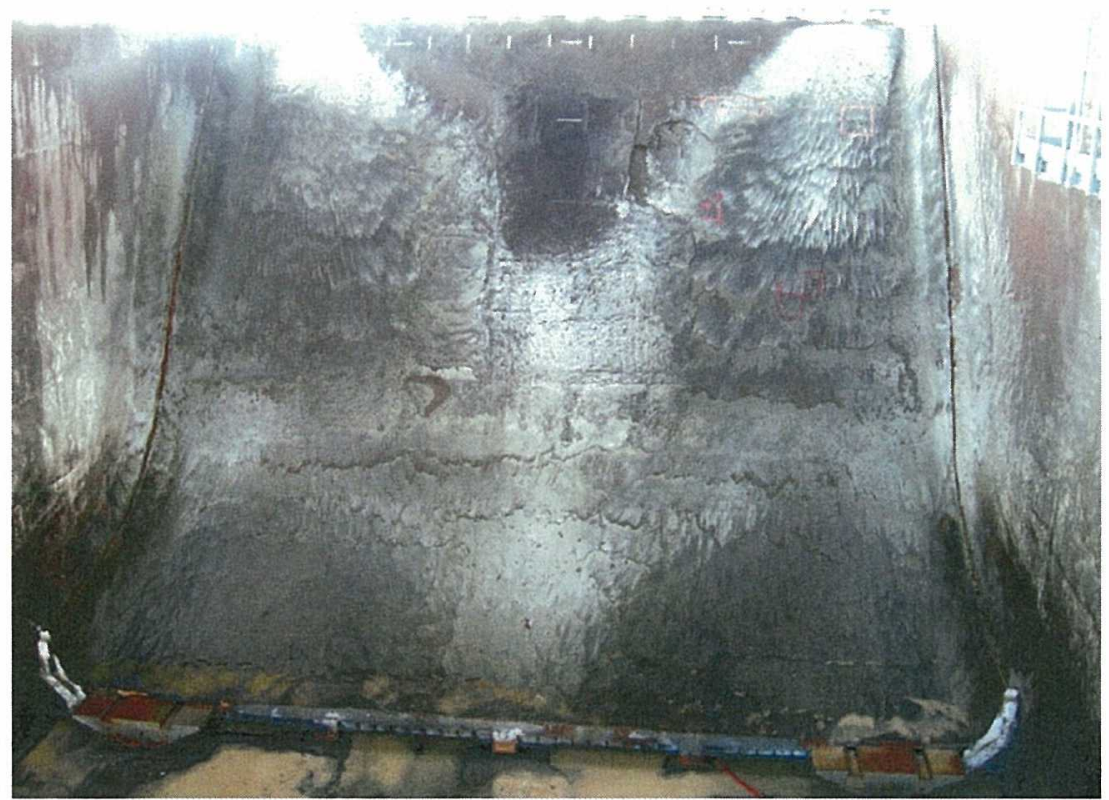

Figure 2. SRB MFD. The light areas at the top left and right are the direct impingement areas.

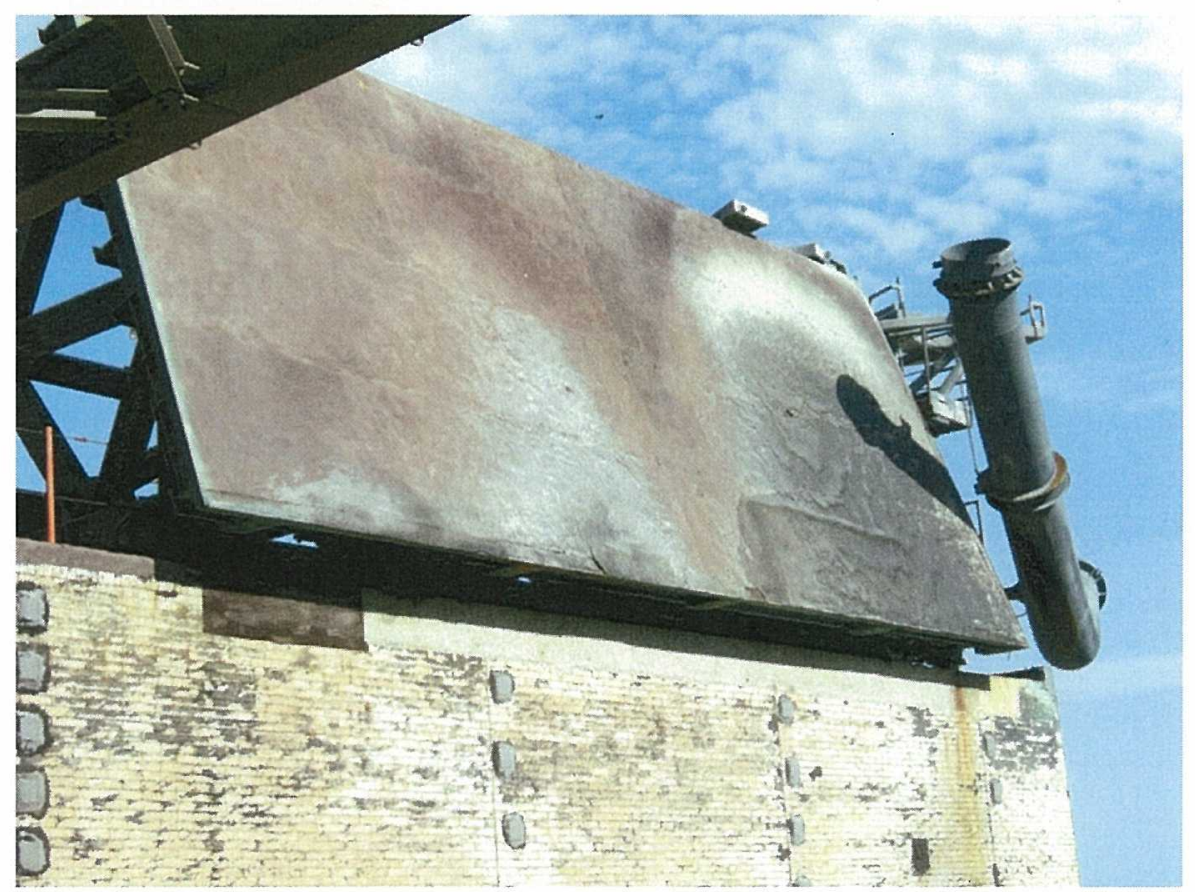

Figure 3. Side flame deflector.

\section{Experimental Methods and Results}

Samples were prepared according to the manufacturer recommended methods. Three materials were evaluated: Fondu Fyre WA-1G, Kruzite GR Plus and Ultra-Tek FS Gun Mix. All three materials were applied by the gunite method and then sectioned to the appropriate size for physical testing. Samples of each material were prepared by an off site contractor. In addition, a set of samples of Fondu Fyre were prepared during a repair at the KSC launch pads, so comparisons between two application locations and times could be made. These samples will be referred to as "Fondu Fyre Pad." 


\section{A. Bulk Density and Porosity}

These measurements were performed according to ASTM C20: Standard Test Methods for Apparent Porosity, Water Absorption, Apparent Specific Gravity, and Bulk Density of Burned Refractory Brick and Shapes by Boiling Water ${ }^{4}$. Cylinders of refractory material having a height and diameter of 2 inches were used for this testing. The samples where dried at $105^{\circ} \mathrm{C}$ and the dry weight recorded. The samples where then placed in boiling water for two hours and allowed to soak in the water for at least 12 hours. The suspended weight and saturated weight were then measured according to the standard.

The results of porosity and bulk density test are shown in Figure 4Figure 4 and Figure 5 . These properties are not considered key performance parameters for the material, but are necessary for structural assessments and quality control of the material.

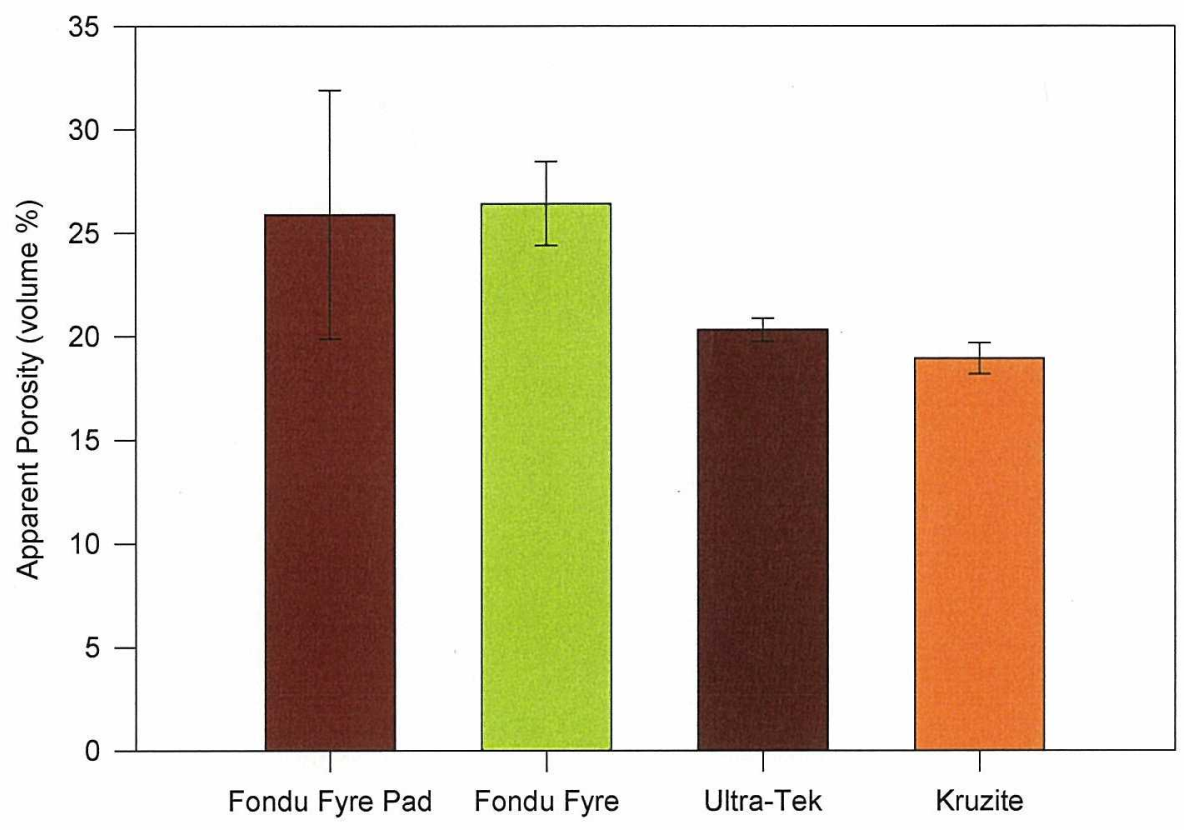

Figure 4. Apparent porosity (volume \%) of the refractory materials. 


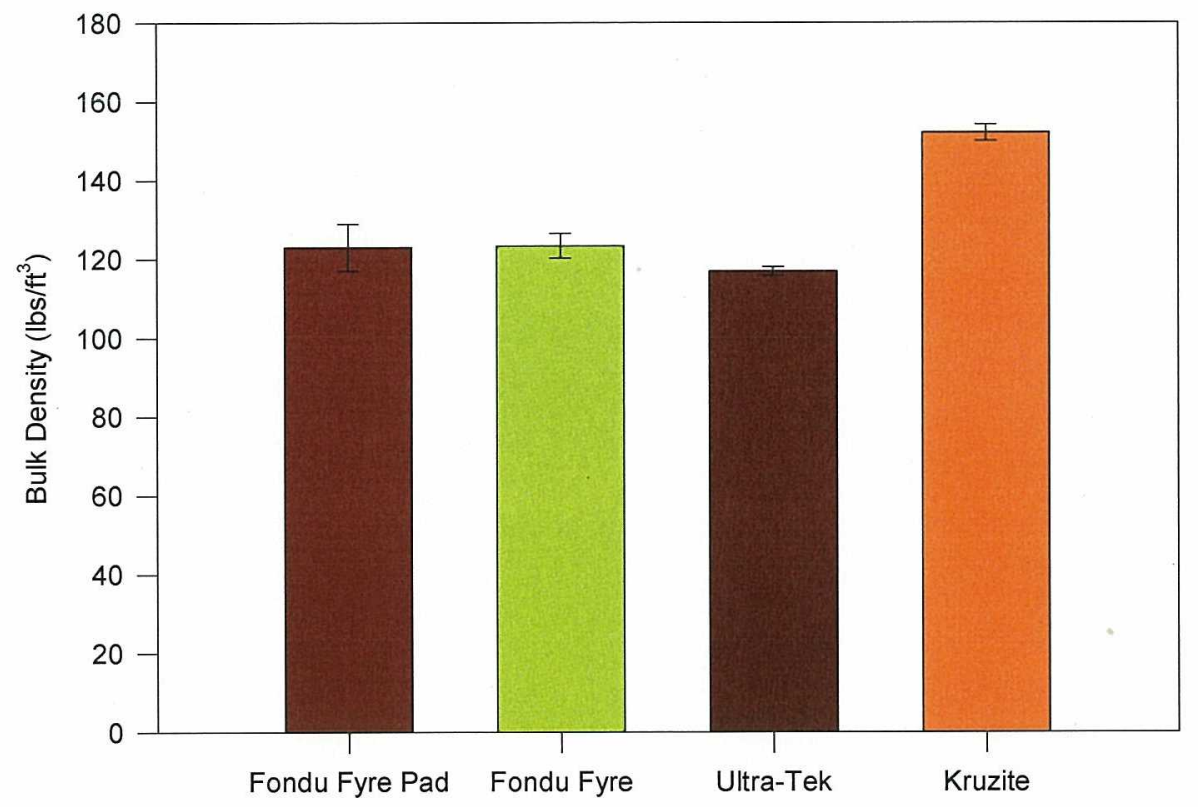

Figure 5. Bulk density $\left(\mathrm{lbs} / \mathrm{ft}^{3}\right)$ of the refractory materials.

\section{B. Modulus of Rupture}

Modulus of rupture measurements were performed according to ASTM C133: Standard Test Methods for Cold Crushing Strength and Modulus of Rupture of Refractories ${ }^{5}$. The measurements were carried out using the Instron Universal Test Machine with $2 \times 2 \times 9$ inch rectangular bars and three stress points with a span of 7 inches.

MOR results are shown in Figure 6. There was a significant difference between the Fondu Fyre samples prepared at different times and locations. Ultra-Tek had a MOR similar to Fondu Fyre. Kruzite GR Plus had the highest MOR.

There is currently no MOR requirement for the refractory material used in the flame trench. However, recent calculations have shown that a MOR value of 570 psi would be satisfactory. It is likely that alternative refractory materials would need to have a MOR value near or above this value.

\section{Compression Strength}

Compression strength was measured on samples that were exposed to four different conditions: 1) a control that was kept indoors; 2) samples that were exposed at the Corrosion Technology Laboratory Beachside Atmospheric Exposure Facility; 3) samples submerged in water for 1 month; and 4) samples submerged in $0.1 \mathrm{M}$ hydrochloric acid for 10 days.

Atmospheric exposure samples were placed in the open at the exposure facility. Samples were sprayed with seawater for 15 minutes of every hour during the atmospheric exposure period.

The acid submersion procedure consisted of the following steps. First the samples were dried in an oven at 105 ${ }^{\circ} \mathrm{C}$ overnight. Each sample was then placed in a container of $0.1 \mathrm{M}$ hydrochloric acid. The acid solution was changed after six days.

Compression strengths were measured according to ASTM C133 ${ }^{5}$ and are shown in Figure 7. Kruzite GR Plus was the strongest material for all exposure conditions. Acid exposure always resulted in the weakest samples for each material. A one way ANOVA was run on results from the different exposures for each material to determine statistical differences in strength resulting from the exposure. Atmospheric exposure did not result in a change in strength for any of the materials. Strength after acid submersion was lower by $14 \%$ for Ultra-Tek FS gun mix. The strength difference after acid exposure was insignificant for the other materials. Water submersion resulted in a significant decrease in strength for all materials. Fondu Fyre had the greatest decrease of about $45 \%$ for both batches of samples. Ultra-Tek had a decrease of 30\%, while Kruzite GR Plus had the smallest decrease of $21 \%$. 


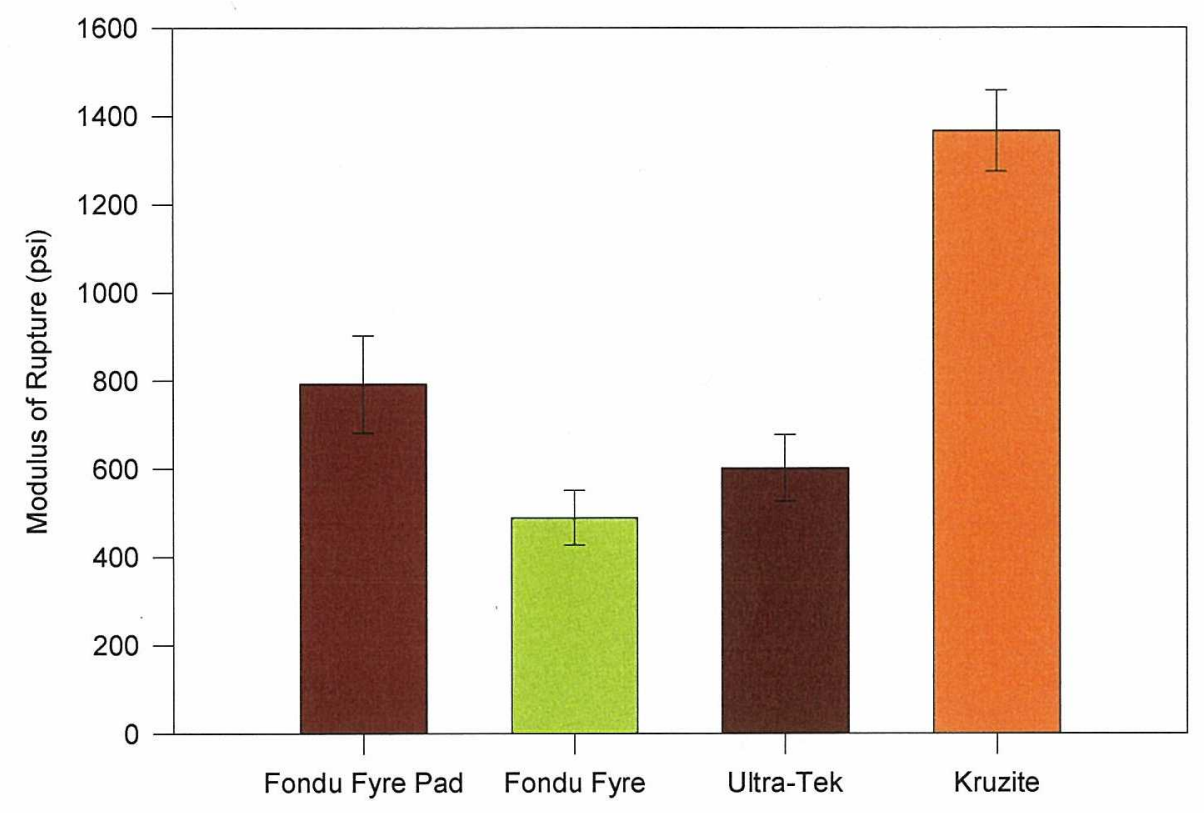

Figure 6. Modulus of rupture (psi) of the refractory materials.

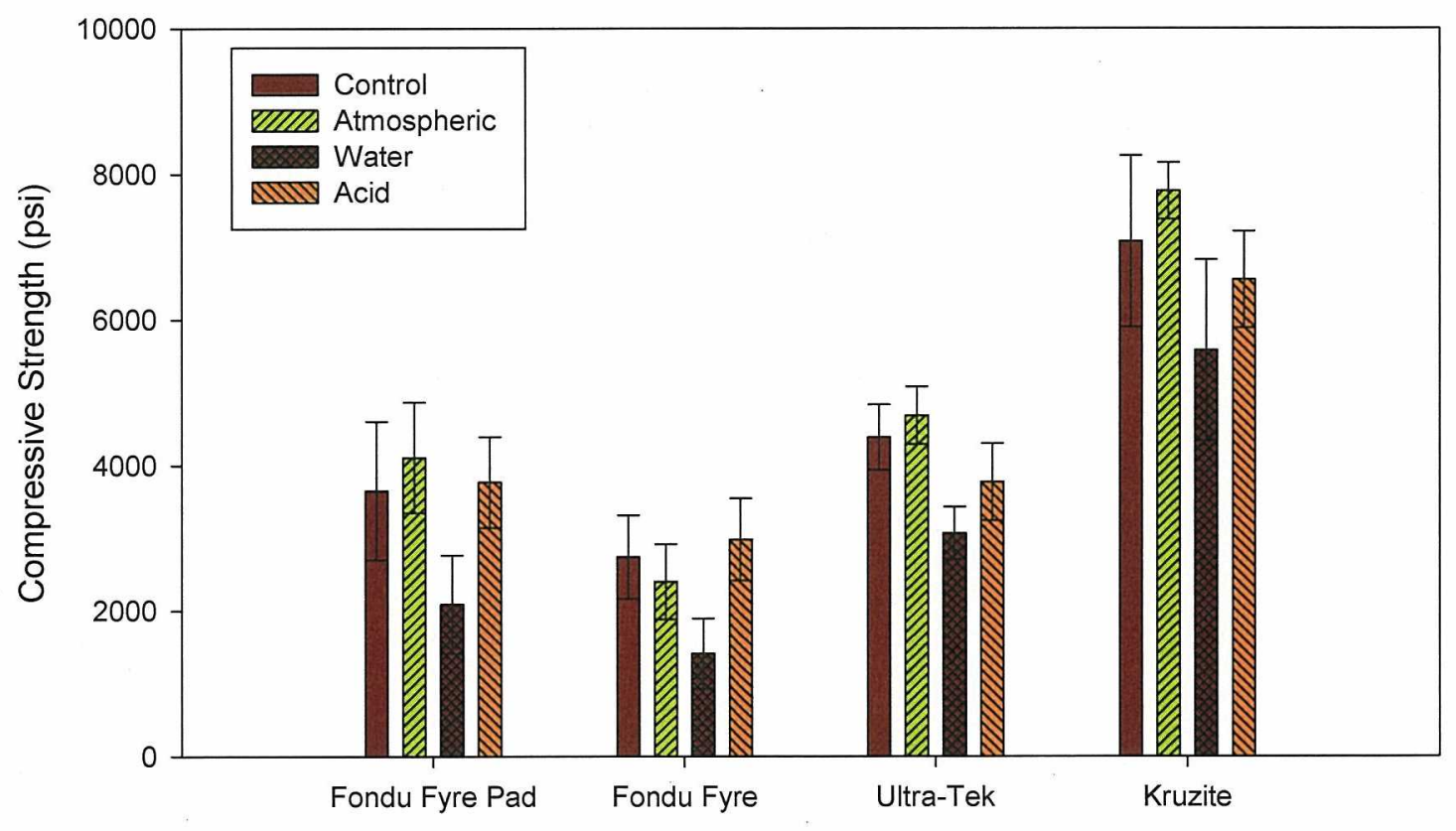

Figure 7. Compression strengths (psi) of the refractory materials after exposure to different conditions. 


\section{Thermal Shock}

Thermal shock testing similar to ASTM C $1171^{6}$ was performed. The samples consisted of bars of material with dimensions $1 \times 1 \times 6$ inches. The bars were subjected to 3 thermal cycles of 15 minutes in an $1100{ }^{\circ} \mathrm{C}$ furnace followed by 10 minutes at room temperature. Five specimens of each material were subjected to this procedure and compared with five specimens which did not see thermal cycling. The MOR of each specimen was measured and used to compare the shocked specimens with the control. Average MOR values are shown in Figure 8, with percent reduction of MOR annotated above the shock value for each material. Kruzite GR plus had the highest MOR values for the control specimens. After thermal shock, Kruzite GR plus and the two Fondu Fyre specimens had lost considerable strength while the Ultra-Tek specimens retained most of their strength. The MOR value for Kruzite after thermal shock was similar to the Fondu Fyre controls.

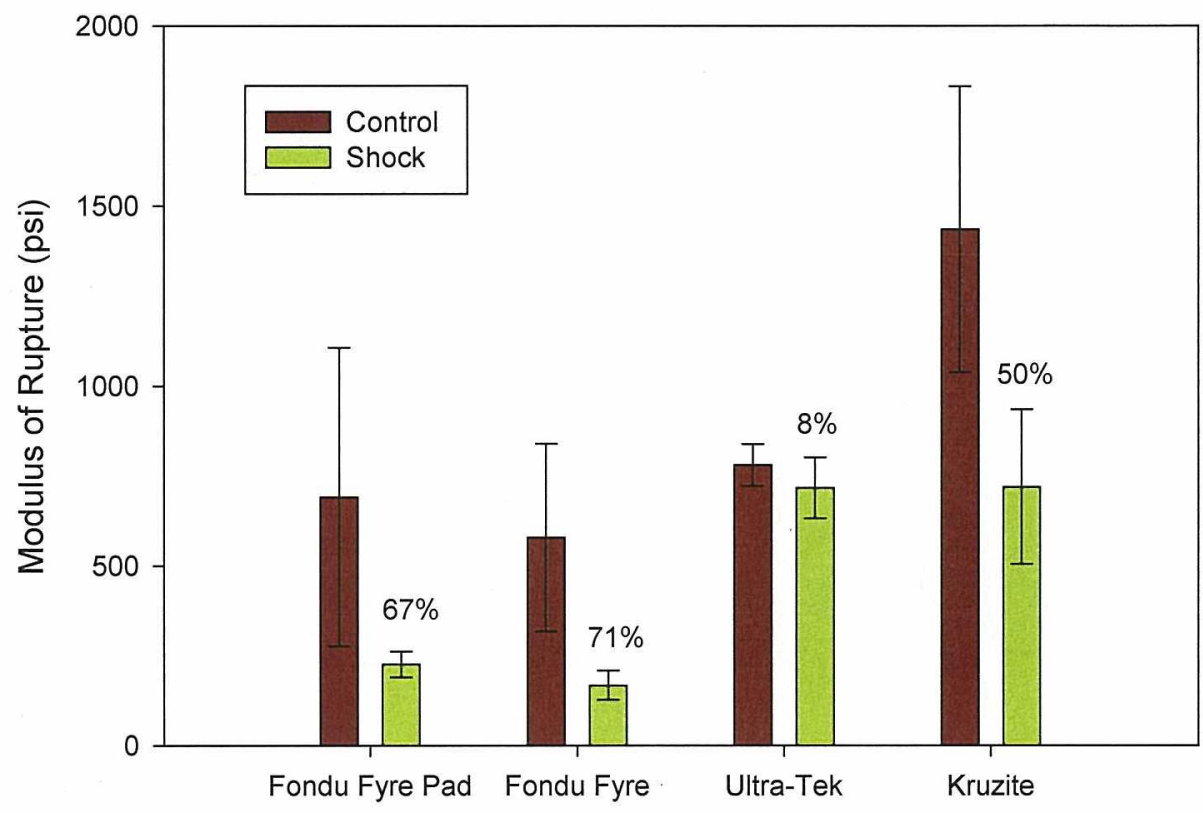

Figure 8. Modulus of rupture (psi) values for control and thermal shock specimens with percent reduction of MOR after thermal shock for each material.

\section{Conclusion}

The flame trench at the KSC Space Shuttle Launch Complex is a unique environment for a refractory material. The combination of seacost environment, acidic rocket exhaust, vibrations and thermal conditions can be detrimental to materials that normally see a more controlled environment. Currently, Fondu Fyre is the only approved material for use at the flame trench. The current material specification may not adequately describe the launch condtions or call out the appropriate key performance parameters that determine if a material will hold up to the environment. The tests performed in this study were selected to better evaluate the materials for the conditions experienced in the flame trench, including exposure to water and acid. MOR was evaluated because models of the forces in the trench, and actual measurements during launch, have shown that the refractory material is placed in tension during launch. It is thought that these tests may in the future be used to help evaluate new materials for use at KSC.

The two alternate materials performed as well or better than Fondu Fyre in the tests performed in this study. Compression strengths and MOR were as strong or stronger. Exposure to water, acid and thermal shock had less effect on Ultra-Tek and Kruzite than on Fondu Fyre. The Fondu Fyre specimens prepared at different locations 
were different from each other, but the differences were consistent with past observations that have shown strength variations for different application times.

\section{Acknowledgments}

The authors would like to acknowledge the financial support of NASA's Exploration Technology Development Program (ETDP) and the Kennedy Space Center Director's discretionary fund. The authors gratefully acknowledge the excellent project management support provided by Nancy Zeitlin, Brekke Coffman, Judith Watson, and Karen Whitley.

\section{References}

${ }^{1}$ http://science.ksc.nasa.gov/facilities/lc39a.html, Last Accessed on December 17, 2008.

${ }^{2}$ http://science.ksc.nasa.gov/shuttle/technology/sts-newsref/stsover-prep.html\#stsover-sound, Last Accessed on March 8, 2010.

${ }^{3}$ http://spaceflight.nasa.gov/shuttle/reference/basics/launch.html, Last Accessed on March 8, 2010.

4"C20 - Standard Test Methods for Apparent Porosity, Water Absorption, Apparent Specific Gravity, and Bulk Density of Burned Refractory Brick and Shapes by Boiling Water", ASTM International, West Conshohocken, PA, 2005.

5"C133 - 97 Standard Test Methods for Cold Crushing Strength and Modulus of Rupture of Refractories", ASTM International, West Conshohocken, PA, 2008.

6"C 1171 - 05 Standard Test Method for Quantitatively Measuring the Effect of Thermal Shock and Thermal Cycling on Refractories", ASTM International, West Conshohocken, PA, 2005. 